Article

\title{
Multilingual Education in the Republic of Kazakhstan: Problems and Prospects
}

\author{
Nurmira Zhumay ${ }^{1, *}$, Saule Tazhibayeva ${ }^{1}$, Azhar Shaldarbekova ${ }^{2}$, Botagoz Jabasheva ${ }^{1}$, Ainur Naimanbay ${ }^{3}$ \\ and Aigul Sandybayeva 4 \\ ${ }^{1}$ Department of Translation Theory and Practice, Faculty of Philology, L. N. Gumilyov Eurasian National University, \\ 010000 Nur-Sultan, Kazakhstan; E-Mails: nurmiraali@mail.ru (N.Z.), sauletazhibaeva@mail.ru (S.T.), \\ botagoz_dzhabash@mail.ru (B.J.) \\ 2 Department of Turkic Studies, Faculty of International Relations, L. N. Gumilyov Eurasian National University, \\ 010000 Nur-Sultan, Kazakhstan; E-Mail: ajars@mail.ru \\ 3 Department of Practical Kazakh language, Faculty of Philology, L. N. Gumilyov Eurasian National University, \\ 010000 Nur-Sultan, Kazakhstan; E-Mail: ainura-1978@mail.ru \\ 4 The Eurasian Humanities Institute, 010000 Nur-Sultan, Kazakhstan; E-Mail: akaleka@mail.ru \\ * Corresponding author
}

Submitted: 10 August 2020 | Accepted: 19 November 2020 | Published: 14 January 2021

\begin{abstract}
The article is devoted to the problem of multilingual education in modern Kazakhstan. Currently, Kazakhstan is fully modernising the education system and introducing a multilingualism policy in the educational process. Experimental sites for multilingual education have been created in several Kazakh universities and secondary schools. The young Kazakhstani generation brought up in independent Kazakhstan is involved in the process of multilingual education. By 2020 it is expected that $100 \%$ of the population will speak Kazakh, $95 \%$ will also speak Russian and $25 \%$ will also speak English. The research results are based on sociolinguistic data that were collected in all regions of the country using sociolinguistic data collection methods.
\end{abstract}

\section{Keywords}

education system; educational institutions; educational process; Kazakhstan; multilingual education; multilingualism policy; youth

\section{Issue}

This article is part of the issue "Social Inclusion and Multilingualism: The Impact of Linguistic Justice, Economy of Language and Language Policy" edited by László Marácz (University of Amsterdam, The Netherlands / L. N. Gumilyov Eurasian National University, Kazakhstan) and Zsombor Csata (Babeș-Bolyai University, Romania / Hungarian Academy of Sciences, Hungary).

(C) 2021 by the authors; licensee Cogitatio (Lisbon, Portugal). This article is licensed under a Creative Commons Attribution 4.0 International License (CC BY).

\section{Introduction}

The Republic of Kazakhstan is carrying out a radical modernisation of the education system and actively introducing a multilingualism policy in the educational process. Not many countries from the Commonwealth of Independent States develop multilingualism at the state level. Most post-Soviet republics from the category of countries with pronounced bilingualism turned their language policy towards monolingualism. In Kazakhstan, multilingualism is developing at the state level in accordance with the tasks set by the Governmental programme of the Republic of Kazakhstan. The initiative of the Head of State is being implemented via the "The Trinity of Languages" project (Aliyasova, \& Kovtunenko, 2012). Multilingualism, as a strategically important task of education, is also set in the State Program for the Development of Education for 2011-2020. By 2020, 
$100 \%$ of the population of Kazakhstan should speak the Kazakh language, 95\% should also speak Russian and 25\% should also speak English (Republic of Kazakhstan, 2010). However, there are also intermediate points of the problem in Kazakhstan.

Now we can state that the formation of Kazakhstan's statehood and civil society is at the beginning of a new stage of development, which is qualitatively different from the previous one: On the one hand, there is every reason to assert that in the first two decades of independence in Kazakhstan, the Kazakhstan model of interethnic and interfaith tolerance was successfully formed. Largely due to this, such strategically important tasks as preserving the independence and territorial integrity of the country, achieving a lasting interethnic and interfaith peace, economic and political stability were successfully solved. On the other hand, at present, the Kazakhstani public and the expert community are realising that interethnic and interfaith peace and harmony as such are only a necessary starting condition for the successful consolidation of society into a single political nation; this awareness of the strategically important task of the new stage of development of the country is reflected in Kazakhstan's doctrine of national unity. Different approaches can be found in the works of Kazakhstani researchers, expressing the main problems of the education system and issues with multilingualism (Aktanov, 2015; Aliyasova \& Kovtunenko, 2012; Amalbekova, 2009). European and West-world practice of studying issues of multilingualism has been divulged in the works of García and Náñez (2011), McLeod and Goldstein (2011), Meyer (2010), Stern (1995) and Trisnawati (2017), among others.

The strategic goal at a new stage of the country's development is not simply to further maintain what has been achieved but to transform the Kazakhstani society into a prosperous new state that can be achieved through knowledge of the original culture and language of the Kazakh people and all other people living in the territory of modern Kazakhstan.

\section{Multilingualism in the Education System}

There are already reasonable results in the development of multilingualism in the education system. In world practice, research on issues related to the problems of multilingualism and multilingual education is studied comprehensively. Multilingual education is under the scrutiny of UNESCO. The American Association of Psychologists conducts special studies on the cognitive abilities of multilingualism in pedagogy and politics. The problems of multilingualism, education and culture have been considered annually at the meetings of the Commission of the European Community since 2007. Moreover, the European Commission provides grants for multilingualism research using e-learning tools such as the Babylon \& Ontology project "Multilingual and Cognitive e-Learning Management System via PDA Phone" (Kubeev \& Zhetpisbaeva, 2008).
An experience in the implementation of multilingual education in the system of secondary and higher education has also accumulated in the Kazakh educational space. This is the experience of multilingual education in Nazarbayev intellectual schools, in Kazakh-Turkish lyceums, in schools for gifted children like the Daryn Centre, among others.

In 2019 there were more than 30 schools with instructions in three languages in the Republic of Kazakhstan. It is planned that 476 schools will switch to a multilingual education system and nine universities of the Republic will train specialists in special disciplines in English. Work has begun on preparing English-language pedagogical staff for secondary, technical and vocational education as part of the Bolashak international scholarship (Zhetpisbayeva \& Arinova, 2012).

L. N. Gumilyov Eurasian National University, like other universities in the country, is working to increase their responsibility and identify key tasks for modernizing the higher education system-an important key to modernizing the system is the training of multilingual staff for the country.

In order to achieve a developed multilingual education and integrate Kazakhstan's national education system into the global economic and educational space, it is necessary to involve a wide range of students in multilingual education, as well as to train multilingual specialists, teachers of secondary schools and universities. This is especially important in connection with the upcoming transition to a 12-year education system.

The study we carried out to define the present state of multilingual education in Kazakhstan showed that some sequential measures should be taken by the government. These are:

1. To study the real situation with multilingual education in the Republic of Kazakhstan.

2. To explore the best international practices in the implementation of multilingual education.

3. To develop a model for the implementation of multilingual education in the aspect of the requirements of the State Program for the Development of Education in the Republic of Kazakhstan for 2011-2020.

4. To develop a model of multilingual specialists by the government for rural secondary schools.

The search for effective ways to train multilingual staff indicates the need to solve the following problems: inconsistency of qualification requirements and characteristics for multilingual specialists; lack of normative and programmatic support for multilingual education; lack of a unified concept for the training of multilingual specialists based on a competency-based approach; insufficient knowledge of the experience of foreign countries concerning the introduction of multilingual education and lack of development of a mechanism for assessing the productivity of a multilingual specialist. 
Multilingual education is inextricably linked with the implementation of the basic parameters of the Bologna process (a process of convergence and harmonisation of higher education systems in European countries aiming to create a single European higher education area) and the correlation and unification of curricula with European standards of education. As an implementation of the concept of the 12-year education system, one of the solutions proposed is the introduction of the foundation program (real 12th grade) with an emphasis on multilingualism and the study of the foundations of basic sciences that will be mastered in the first year of study at a university. In this case, a full bachelor's training course should be five years (one year of foundation program plus four years of bachelor's degree). Starting from the second year, training in specialised disciplines is offered. From our perspectives, specialised disciplines should be studied in the following proportion: half in the state language, one fourth in Russian and one fourth in English for groups with the Kazakh language of education. As for the students receiving education in the Russian language, one fourth of the subjects should be taught in the Kazakh language, half in Russian and one fourth in English. In this case, students can pass a general education unit and enhanced language training. Foundation programs would first solve the problem of multilingual education, then the problem of transition to the 12-year education system and, thirdly, the problem of multilingual staff who will conduct the educational process, solved in the short term. Let us explain what we mean:

1. The modern education system makes high demands on the teaching staff of higher education. The quality of activities is directly related to the quality of training of future specialists. Universities offer the possibility to master English for free. Currently, many faculty members of Kazakhstani universities are fluent in foreign languages. More than 100 faculty members of L. N. Gumilyov Eurasian National University in Nur-Sultan participated in summer language schools over the past two years. Also, they undergo a professional internship in foreign universities. After getting their certificates, the faculty members conduct classes in graduate and post-graduate programs in English. The level of scientific publications of L. N. Gumilyov Eurasian National University faculty members in foreign journals included in the Thomson Reuters and Scopus databases has doubled. This is the evidence of the intensification of multilingual activities of the faculty of our university.

2. The opportunities that international cooperation provides for the training of multilingual staff should be noted. The Ministry of Education and Science also provides great support in attracting well-known foreign scientists to L. N. Gumilyov Eurasian National University. In just one academic year, 307 leading professors from 40 countries of the world conducted a cycle of disciplines for students attending our university. The expansion of this kind of interaction allows increasing the competitiveness of future specialists, as well as improving the quality of multilingual staff. Another form of international cooperation is the international scholarship Bolashak granted by the President of the Republic of Kazakhstan. In L. N. Gumilyov Eurasian National University, under the Bolashak scholarship, more than 200 teachers undergo international internships at top universities in the world every year. Some activities are also being held at L. N. Gumilyov Eurasian National University to prepare an educational and methodological complex of disciplines in the Kazakh, Russian and English languages. There are plans to conduct specialised copyright programs in foreign languages in fundamental areas of science.

3. Moreover, in Kazakhstan, large-scale financing of programs of external academic mobility of students in Kazakhstani universities has been launched. During the academic period, they will be studying abroad at the expense of the state. Undoubtedly, training programs within the framework of students' academic mobility should be integrated into the multilingual training system. This is an effective way of training multilingual staff, as students of all specialities, from all regional universities around the country, are involved in the program of academic mobility.

4. Another way to effectively carry out the primary training of multilingual staff is the inclusion on the list of basic disciplines of standard curricula of disciplines such as "ProfessionallyOriented Foreign Language" and "Professional Kazakh/Russian." In the context of multilingualism, the state compulsory education standard of pedagogical specialities has also been developed, providing for specialisation in the preparation of a subject teacher with knowledge of a foreign language.

\section{The Role of Kazakh and Russian Languages in Education}

In the multilingual process, a large role is given to the state and the official language. At present, a generation of Kazakh-speaking Kazakh youth, both rural and urban, has already grown up to enter "the big life" - an idea formed in the years of the independence, from the mid- to late-1980s. They have graduated from schools with the Kazakh language of education and have continued education in universities mainly with courses in the Kazakh language. Students from the younger gen- 
eration have rather serious social expectations regarding their linguistic sphere and develop an appropriate behaviour strategy. Unlike their parents, they react much more painfully and actively to the fact that a significant part of their fellow citizens does not speak or even understand Kazakh.

The following can be said about the social expectations of this youth contingent in the context of the language policy of Kazakhstan from 1990 to the present: Regardless of how realistic and doable these expectations are today they already exist and will not disappear. The idea of the Kazakh language becoming the state language has become the property of public consciousness and has already been taken seriously by a significant part of society.

The state strictly monitors the implementation of the "Law on Languages." Before our eyes, there are cardinal changes in the expansion of the functions of the Kazakh language. The Russian-speaking population of our Republic-by which we mean Kazakhs who do not speak their native language-which are mainly concentrated in large cities, must not only master the Kazakh language but also communicate and answer test questions and be able to think in this language. Therefore, our task in this matter is to attract the Russian-speaking population to the study of Kazakh culture and their active involvement in educational and cultural life in the state language. It is necessary to support the life of the Kazakh language as the language of natural national creativity.

The implementation of the main tasks of multilingual education under the State Program for the development of education in the Republic of Kazakhstan (Republic of Kazakhstan, 2010), as we all understand, requires wellconsidered organisational and institutional mechanisms. That is why it is necessary to create a coordinating scientific and methodological Republican centre (institute) for the development of multilingualism, the tasks of which will become: analysis of the language situation in educational institutions; development of the conceptual foundations of multilingual education and training of multilingual staff; organisation of a pedagogical experiment to improve teaching in three languages, as well as dissemination of the results of the experiment and the use of e-learning for effective training of multilingual staff.

Such a coordinating centre can be the L. N. Gumilyov Eurasian National University and among the pedagogical universities of the Republic the Abay Pedagogical National University in Almaty and Nazarbayev University in Nur-Sultan. The methodological recommendations developed by the Centre for the effective implementation of multilingual education and the training of multilingual staff can later be used in the activities of the Ministry of Education and Science of the Kazakhstan Republic, as well as used in the system of training and advanced training of teachers and senior educators through seminars and continuing education courses.

Due to its multifaceted and multidimensional nature, the problem of multilingualism requires the attention of scientists from various scientific schools. Therefore, the Centre for multilingualism should be multidisciplinary. The implementation of multilingualism needs constant scientific support. In this regard, it is necessary to analyse the sociolinguistic and intercultural factors affecting the development of multilingualism in the Republic of Kazakhstan. This will make it possible to identify the real situation of multilingual education to further prepare proposals and comments on the training of multilingual staff.

It is necessary to study the advanced multilingual experience of leading countries (Canada, USA, France, Switzerland, Belgium, Finland, Singapore and Malaysia). The systematisation and generalisation of the world experience of multilingual education and the introduction into practise of effective teaching methods by educational level will allow the Centre of multilingualism to develop detailed proposals for introducing the most modern teaching methods and technologies into the multilingual education process, provide an increase in the level of professionalism of teachers, which in turn will affect the quality of training of multilingual staff and increase the competitiveness of alternative language educational programs.

We think that it is necessary to comprehensively disseminate the experience of Kazakhstani universities for the effective training of multilingual staff in various fields, to develop common solutions and proposals.

The study of languages in the educational system of Kazakhstan has a well-established tradition: Teaching material for Kazakh and Russian as a second foreign language is developed by the faculty of leading Kazakhstan universities-Al-Farabi Kazakh National University, Abay Kazakh Pedagogical University and Abylay Khan Kazakh University of International Relations and World Languages. The experimental sites for the implementation of multilingual education in our Republic are the E. A. Buketov Karaganda State University (Karagandy) and Abylay Khan Kazakh University of International Relations and World Languages (Almaty). International Associations for Intercultural Communication, which closely monitor the development of language policy in the Republic of Kazakhstan, are interested in the theoretical and methodological base being developed.

\section{New Challenges in Translation}

The independence of the Republic of Kazakhstan has resulted in the development of trilingualism (Kazakh, Russian and English) in higher education. It has also led to the advancement of literary translation as well. Before Kazakhstani independence, specialists in Translation had never been prepared in Kazakhstan. Kazakh writers' literary works were translated from Kazakh into Russian and then through the intermediary Russian language to other foreign languages such as English, German, French, Turkish, Arabic, Korean, Japanese, etc. However, after gaining independence, the increase in the num- 
ber of translators who mastered foreign languages as well as their mother tongue enabled them to translate imaginative writings directly from Kazakh into different languages such as English, German, French, Turkish, Arabic, Korean, Japanese, among others. In this way, Kazakh literature, Kazakh culture, Kazakh customs and traditions spread to foreign readers.

The following activities were implemented in the field of translation studies after the independence of the country (see Table 1).

Here, the most important thing is that the main literary works were translated into English or vice versa via intermediary Russian language before Kazakhstan gained its independence. Nonetheless, after gaining independence, the increase in the number of translators who mastered foreign languages as well as their mother tongue enabled the translation of imaginative writings directly from English into Kazakh or from Kazakh into English. Thus, the field of domestic translation studies achieved positive results. In recent years, a lot of research has been done on existent types of translation, including the translation of literary works from
Kazakh into English (see, e.g., Zhumay, Maira, Zhunissova, Zhunissova, \& Zhazira, 2020).

\section{Conclusion}

The comprehensive introduction of multilingual education for a wide range of students in the Republic, the training of multilingual specialists and the training of multilingual personnel for the training of future specialists are strategically important tasks that the universities of the Republic of Kazakhstan Ministry of Education and Science must take on, and they can do so through joint efforts.

The realities of today are such that we, university teachers, actively implement the tasks of reforming the education system on a daily basis. Therefore, we sincerely hope that our joint active work will be embodied in a society built by competitive multilingual staff.

In our opinion, multilingualism contributes to the development of a dynamic personality for the future, an increase in the level of education of citizens, increasing their overall cultural level, and the development

Table 1. Published works in the sphere of translation studies after the independence of the Republic of Kazakhstan, in 1991.

\begin{tabular}{lll}
\hline No. & Sponsors & Published works \\
\hline 1 & $\begin{array}{l}\text { The Ruhani zhangiru ("spiritual } \\
\text { revival") program of the } \\
\text { National translation bureau }\end{array}$ & $\begin{array}{l}\text { Zhana gumanitarlik bilim. Kazak tilindegi } 100 \text { zhana okulik ("New Humanitarian } \\
\text { Knowledge: } 100 \text { New Books in the Kazakh Language"). }\end{array}$ \\
2 & $\begin{array}{l}\text { The Madeni mura ("cultural } \\
\text { heritage") program, on-going } \\
\text { since } 2004\end{array}$ & $\begin{array}{l}537 \text { books were published in total: Babalar sozi ("Ancestors Words"; } \\
100 \text { volumes); Zhuz Qazaq romany ("Hundred Kazakh Novels"; } 200 \text { volumes); } \\
10 \text { volume Kazakhstan encyclopaedias (five of which were published in Russian } \\
\text { and in English); Al Farabi's works (20 volumes). }\end{array}$
\end{tabular}

3 Audarma (publishing house)

21 main works of Kazakh writers were translated into English.

$4 \quad$ The Altin kopir translators contest held in 2009, sponsored by the Ministry of Culture and Sport

5 The Pen Club program

6 The Anthology of Contemporary Kazakh literature state program

7 The National Translation Bureau

8 The Zhahandagi zamanui Kazakstandik madeniet ("Contemporary and global Kazakhstani culture") program

9 Atamura (publishing house)
Several works in the poetry and prose genres, authored by the contest winners, were translated into the Kazakh and Russian languages.

13 novels by Kazakh writers were translated into English.

An anthology of contemporary Kazakh literature was translated, including tales such as: The Stories of the Great Steppe (2013), Summer Evening, Prairie Night, Land of Golden Wheat (2015); The Outside World in Kazakh Literature (2015).

Ilyas Zhansugurov's poem Kulager (translated by Belinda Kuk).

The aim of the program was to translate imaginative Kazakh writings into six UN languages. The work of 60 Kazakh authors, in the poetry and prose genres, were translated.

Kazakh Customs and Traditions (2015), Kazakh dastarkhan (2011), Alpamys Batyr (2014), Koblandy Batyr (2014), Kozy Korpesh-Bayan Sulu (2011). 
of their readiness for international and intercultural cooperation.

The conducted research and the results obtained do not claim to be an exhaustive solution to all aspects of multilingual education. Prospects for further developments can be expressed in the study include the problems of continuity of multilingual education at different levels of the education system, comparative aspects of teaching Kazakh, English and Russian, lingua-didactic aspects of the development and compilation of educational and methodological complexes of not only linguistic but also non-linguistic disciplines, lingua-didactics as a methodological guideline in the development of the content of modern multilingual education and foreign experience in teaching multilingualism, among others.

\section{Acknowledgments}

We thank our colleagues from L. N. Gumilyov Eurasian National University, who provided insight and expertise that greatly assisted the research.

\section{Conflict of Interests}

The authors declare no conflict of interests.

\section{References}

Aktanov, D. (2015). The language policy of Kazakhstan. Gumilev Center. Retrieved from https://www. gumilev-center.ru/yazykovaya-politika-kazakhstana

Aliyasova, A. V., \& Kovtunenko, V. A. (2012). Cultural project "Trinity of Languages" as the implementation of the idea of multilingual education in Kazakhstan. Pavlodar: Pavlodar State University Press.

Amalbekova, M. B. (2009). Peculiarity of bilinguals in
Kazakhstan. Astana: Eurasian National University Press.

García, E. E., \& Náñez, J. E. (2011). Bilingualism and cognition: Informing research, pedagogy and policy. Washington, DC: American Psychological Association.

Kubeev, E. K., \& Zhetpisbaeva, B. A. (2008). Multilingual education concept. Karaganda: Karaganda State University Press.

McLeod, S., \& Goldstein, B. (2011). Multilingual aspects of speech sound disorders in children. Bristol: Communication Disorders across Languages.

Meyer, B. (2010). Multilingualism at work: From policies to practices in public, medical and business settings. Amsterdam: John Benjamins Publishing Company.

Republic of Kazakhstan. (2010). State program for the development of education of the Republic of Kazakhstan for 2011-2020. Astana: Republic of Kazakhstan. Retrieved from http://planipolis.iiep. unesco.org/sites/planipolis/files/ressources/ kazakhstan_state_program-of-educationdevelopment-in-the-republic-of-kazakhstan_20112020.pdf

Stern, P. (1995). Why do people sacrifice for their nations? Political Psychology, 16(2), 217-235.

Trisnawati, I. K. (2017). Maintaining the identity of bilingual individuals in multicultural/multilingual settings. Englisia, 5(1), 8-16.

Zhetpisbayeva, B., \& Arinova, O. (2012). From the idea of "Trinity of Languages": N. A. Nazarbayev to multilingual education in Kazakhstan. Vestnik KarGU, 4(68), 19-23. Retrieved from https://pedagogy-vestnik.ksu. kz/apart/srch/2012_pedagogics_4_68_2012.pdf

Zhumay, N., Maira, G. T. Z., Zhunissova, A., Zhunissova, J. A., \& Zhazira, S. (2020). Lexemes with the "camel" component in Kazakh: Problems of translation. Opción, 36(27), 1660-1674.

\section{About the Authors}

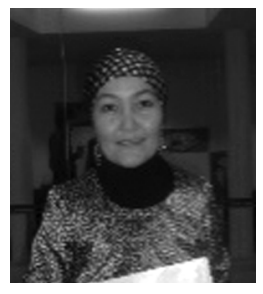

Nurmira Zhumay is a PhD student at the Department of Translation Theory and Practice, Philological Faculty, L. N. Gumilyov Eurasian National University. She completed her internship programs at Leiden University (2014) and Amsterdam University (2019). Her main research interests are actual problems of translation studies and Kazakh, Russian and English comparative and contrastive linguistics. She is the author of several research articles on these topics.

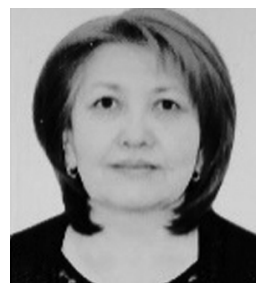

Saule Tazhibayeva is Professor Doctor of Philology at the Department of Translation Theory and Practice, Philological Faculty, L. N. Gumilyov Eurasian National University. Her main research interests are general linguistics, Turkology, computer linguistics and Kazakh, Russian and English comparative and contrastive linguistics. She is the author of research articles and monographs on Turkic languages, cross-subject and multidimensional studies published in Kazakhstan and abroad. She supervised the project "Turkic World of Kazakhstan: Language Variants, Cultural Archetypes and Self-Identification of Turkish Diaspora" granted by the Ministry of Education and Science of the Republic of Kazakhstan (2015-2017) and co-supervised the project "Interaction of Turkic Languages in the Post-Soviet Kazakhstan," jointly funded by the Volkswagen Foundation (2014-2018). 


\section{COGITATIO}

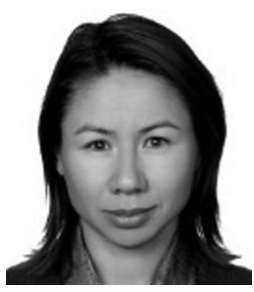

Azhar Shaldarbekova (PhD) is Associate Professor in the Department of Turkology at L. N. Gumilyev Eurasian National University. After earning her MA in History from the Department of History at A. Yassawi IKTU, in 1996, she completed a PhD in History from the Department of Ancient Languages and Civilizations (Sumerology) at the University of Ankara (Turkey) in 2005. Her scientific interests include history of Ancient civilization, Ancient Anatolian history, Ancient Turkic history, source studies and methods of historical research. She was Senior Researcher in the project "The Turkic World of Kazakhstan: Language Variants, Cultural Archetypes, Self-Identification of Turkish Diaspora" and Reader in "Methods of Historical and Archaeological Research of Ancient Turkic Runic Inscriptions," "Ancient Turkic Civilization" and "Ethnopolitical Factors of Formation of Turkic People."

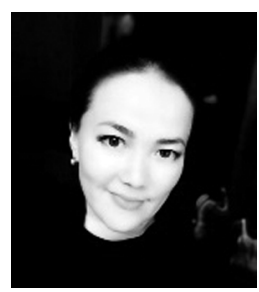

Botagoz Jabasheva is a Senior Teacher at the Department of Translation Theory and Practice, Philology Faculty, L. N. Gumilyev Eurasian National University. Her main research interests are education, educational leadership and management and comparative and contrastive linguistics. She did her MA at the University of Warwick in educational leadership and management speciality. Her thesis was about transformational leadership.

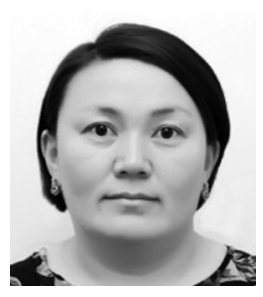

Ainur Naimanbay holds a PhD in Philological Sciences and is Associate Professor at the Department of Practical Kazakh Language of the L. N. Gumilyov Eurasian National University. She is engaged in communicative grammar, lexicology, and stylistics of Kazakh linguistics. Her scientific and methodological articles have been published in national and international publications. She is the author of two textbooks and participates in research projects. In 2011, she worked as a teacher of the Kazakh language at the Department of Turkology of the Yerevan State University of the Republic of Armenia. She won of the Republican contest "Best Teacher of Kazakhstan," announced by the Ministry of Education and Science of the Republic of Kazakhstan.

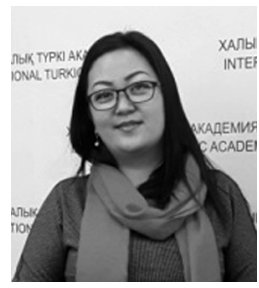

Aigul Sandybayeva is a Master of Pedagogical Sciences, Senior Lecturer of the Department of Kazakh and Russian Philology of the Eurasian Humanities Institute. Her scientific interest is in the field of Turkic studies, Kazakh philology, comparative grammar and vocabulary of the Turkic languages. She is the author of scientific articles in the field of lexicology of Turkic words, in particular, the polysemy of words in the work of Mahmud Kashkary Divani lugat it-Turks. She is the author of the textbook for students Subject of Action (Based on Scientific Discourse (2014). 